\title{
Distribution and determinants of young child feeding practices in the East African region: demographic health survey data analysis from 2008-2011
}

Constance A Gewa ${ }^{1 *}$ and Timothy F Leslie ${ }^{2}$

\begin{abstract}
We utilized the most recent Demographic Health Survey data to explore the distribution of feeding practices and examine relationships between complementary feeding and socio-demographic and health behaviour indicators in Kenya, Uganda and Tanzania. We based our analysis on complementary dietary diversity scores calculated for children 6-23 months old. Geographically, Kenya displayed clear division of children's diet diversity scores across its regions, unlike Uganda and Tanzania. Less than 40\% of the children's meal frequencies in Uganda and Tanzania had met the minimum daily recommended levels. Only 30-40\% of children in Kenya, Tanzania and Uganda had consumed diets with adequate diversity. Children's age, breastfeeding status, mother's education level and working status, household wealth index, prenatal care visits, receiving vitamin A supplements, using modern contraceptives and meal frequencies were significantly associated with adequate complementary food diversity in at least one of the three countries included in the current analyses. These analyses contribute to a better understanding and targeting of infant and young child feeding within the East African region.
\end{abstract}

Keywords: Infant and young child feeding, Complementary feeding, Kenya, Uganda, Tanzania, East Africa

\section{Background}

Undernutrition accounts for $35 \%$ of deaths among children less than five years of age, with a vast majority of these losses reported in Africa and Asia [1]. The first two years of life is a critical period characterized by high rates of growth and development and accompanying high nutritional requirements [2]. Research has shown that exclusive breast-feeding adequately provides for children's energy and nutrient needs in the first six months of life [3]. However breast-milk alone cannot meet the increased energy and nutrient requirements as children get older [3]. Thus, the World Health Organization (WHO) recommends that infants should be exclusively breastfed for the first 6 months of life, after which they are introduced to appropriate complementary foods as they continue to

\footnotetext{
*Correspondence: cgewa@gmu.edu

'Department of Nutrition and Food Studies, George Mason University, 4400 University Dr. MSN 1F8, Fairfax, VA 22030, USA

Full list of author information is available at the end of the article
}

breastfeed $[4,5]$. Consumption of adequate non-breastmilk foods contribute to improved growth, health and development of young children [6-9]. The WHO recommendations call for timely introduction of nutritionally adequate, appropriate, and safe foods for all children, and further indicate that a variety of foods should be consumed to ensure children's nutrient needs are met [10]. Furthermore, animal-source foods and vitamin Arich fruits and vegetables should be eaten daily or as often as possible [10]. While the recommendations do not vary across countries, the application of these recommendations is more critical in low-income nations that bear the larger burden of child malnutrition and limited resources [11-13].

In this paper, we investigated infant and young child feeding (IYCF) within three countries in East Africa: Kenya, Uganda and Tanzania. These countries have an unusually strong relationship besides their shared borders. They have similar weather and geological patterns with agriculture and tourism forming the backbone of 
their economies and have been long-term trade partners and consult each other on matters regarding policy, trade, and marketing [14]. Despite these similarities, child malnutrition rates vary greatly across the three countries [15]. With respect to child nutrition, Uganda has experienced a substantial decline in stunting prevalence from $45 \%$ in $2000 / 01$ to $33 \%$ in 2011, while stunting rates have remained unchanged at above $40 \%$ in Kenya and above $35 \%$ in Tanzania over a similar time-period [15]. Understanding the role of various factors in determining IYCF contributes to knowledge needed in achieving improved child nutrition in these countries. Within the past several years, all three countries have defined policies to protect, promote and support appropriate IYCF practices [16-20]. Translation of policies to actual practice is complex and is often influenced by both micro-and macro-level factors [21]. Understanding the determinants of IYCF would help contribute to knowledge needed to improve child feeding environment and child nutrition in these countries. To our knowledge, documented studies on determinants of infant and young children's DDS are generally lacking in Uganda and Tanzania while the more recent studies that have been conducted in Kenya have focused on specific regions within the country $[22,23]$. There is need to update the literature on this region using recent national sample data. Our objectives were to assess the geographical distribution of complementary feeding practices, and examine the relationship between select socio-economic, demographic and health-care utilization indicators, and complementary feeding practices within Kenya, Uganda and Tanzania.

\section{Methods}

This analysis utilized secondary data from the standard DHS data collected nationwide in Kenya in 2008/09, Uganda in 2011, and Tanzania in 2010. Within each country, representative probability samples were selected by DHS using a multistage stratified cluster sampling methodology [15]. The DHS sample sizes were calculated to account for separate key indicators [15,24]. Clusters were selected from the master frames in the first stage via the probability proportion to size method. Households were then selected from a sampling frame using a random systematic method $[15,25]$. Representative samples of 10000, 10086 and 10300 households were drawn for surveys in Kenya, Uganda and Tanzania respectively [15]. Informed consent was obtained from each lead respondent, within the household, prior to questionnaire administration [15]. The ICF (Inner City Fund) International's Institutional Review Board approved the DHS protocol. Survey response rates fell between $96 \%$ and 99\% across the years for all countries of interest. Data was weighted to cater for different sample proportions across regions.
Figure 1 portrays the mapped distribution of DHS collection points. Uganda's sampling is the densest, avoiding only Lake Victoria in the southeast. Tanzania has several large game reserves with no sampled populations. Kenya has clear regional selections. In Kenya, almost all DHS observations were taken from the central and southwestern parts of the country. Included on the figures are the countries' capital cities; for Tanzania, we referenced both the commercial and administrative capitals, Dar es Salaam and Dodoma.

\section{Geographic distribution}

We used cartographic analysis to investigate the spatial trends of diet variety across East Africa. Similar to previous research, we interpolated a surface with the most recent data available across the three countries using a Kriging method, a common interpolation method used to provide a regional understanding of dataset-wide trends $[26,27]$. We calculated the percent of consumption of individual food groups and the mean DDS for each of the 1162 "cluster" location, and then used these scores to estimate diet variety scores for every location using nearby DHS survey sites. The number of individual observations per cluster ranged from 1 to 17 , with an average of 3.9. Although the exact locations of the survey cites were somewhat displaced to preserve respondent anonymity, the final surface incorporated an error term that mitigates the bias introduced by DHS [28].

\section{Complementary feeding practices}

Information on complementary foods consumed by children in the previous 24 hours was available for children between the ages of 0 and 24 months. Caregivers, mostly mothers, were asked to indicate if the target child had consumed selected complementary food within the last 24 hours.

\section{Dietary diversity}

The WHO recommends the use of seven food groups namely grains/roots/tubers; legumes and nuts; dairy products; flesh foods (meats/fish/poultry); eggs; vitamin A-rich fruits and vegetables (VAFV); and other fruits and vegetables (OFV) in defining children's dietary diversity score [29]. However, because the flesh foods and eggs had been combined as a single entry in the Kenyan DHS survey, a decision was made to use the combined meats/fish/ poultry/eggs (MFPEs) food group for children in all three countries. Thus the children's complementary food dietary diversity score (DDS) definition was based on six food groups: (i) grains/roots/tubers, (ii) VAFVs, (iii) OFVs, (iv) legumes and nuts, (v) dairy, including formula and (vi) MFPEs. The DDS was constructed by assigning one point to each of the defined food groups, for a maximum of six points. Because the MFPs and eggs were collected as 
Survey Sites in Kenya, Uganda and Tanzania

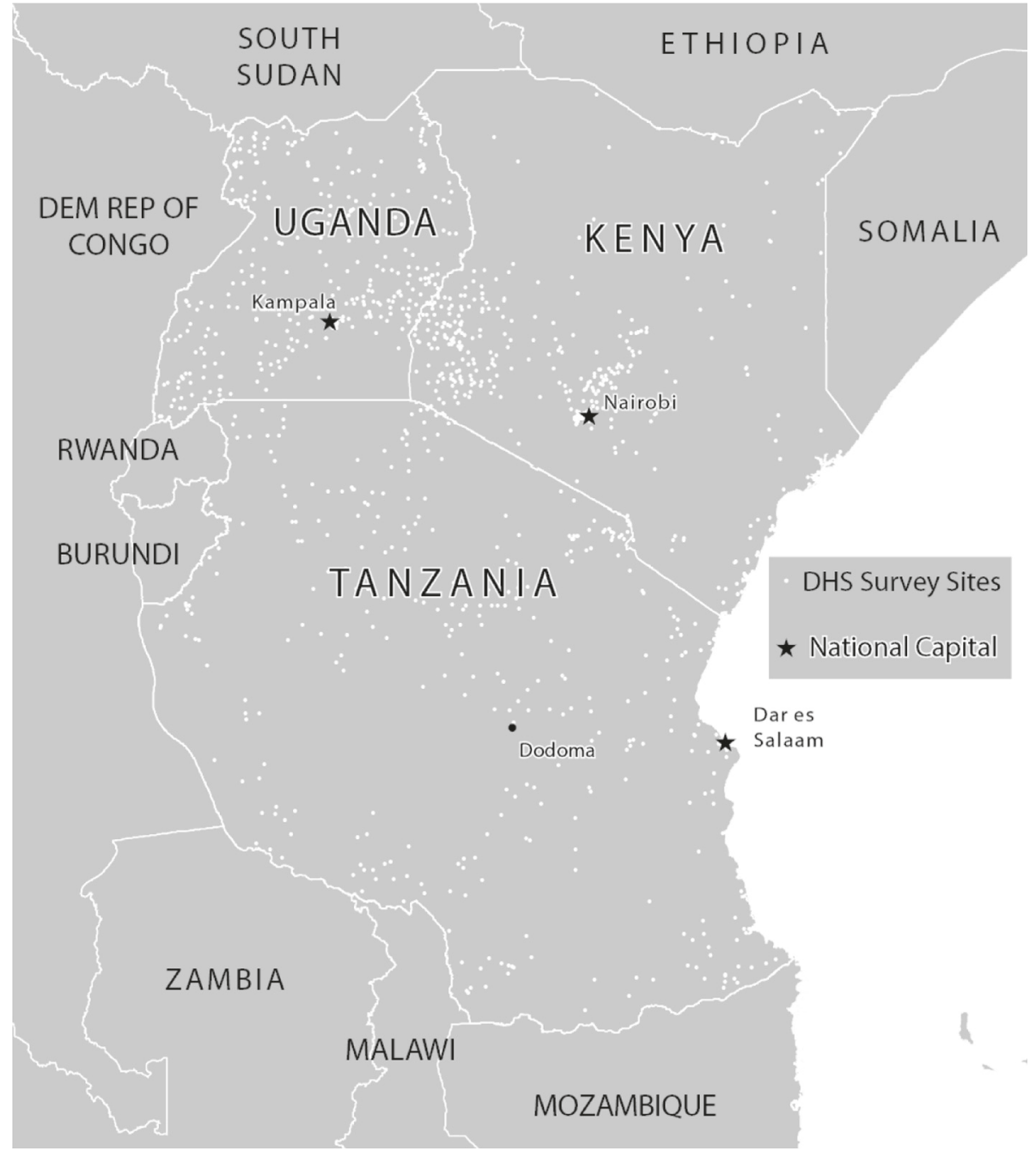

Figure 1 Survey Sites in Kenya, Uganda and Tanzania.

separate variables in the Uganda and Tanzania surveys, a decision was made to assign one point to the MFPEs food group if a child had consumed either MFPs or eggs on the day of reference.

The DDS is a simple but valid dietary assessment tool that has been shown to be a good indicator of micronutrient intake among young children [7,30-32]. Consumption of foods from at least 4 food groups has been associated a high likelihood of a child consuming at least one animal-source food and at least one fruit or vegetable, in addition to a staple food and, has been used to classify diets of children from developing countries [29,33] Drawing from this literature, we defined adequate complementary food dietary diversity as consumption of food from at least four different food groups (DDS $\geq 4)$.

\section{Information collected}

\section{Child factors}

Information was collected on children's ages, birth order, sex, breast-feeding status and morbidity experience. Children's ages were categorized into 9-11, 12-17 and 18-24 months to allow for comparison with previous studies $[29,32]$. Mothers were asked if the children were breastfeeding at the time of the survey. For morbidity experience, respondents were asked to recall if the child had experienced any diarrhea or cough episode in the previous 24 hours or within the two weeks preceding the interview.

\section{Socio-economic and demographic factors}

The sex of the household head was identified in the survey. Information was collected on mothers' age, marital status (married, living with partner, or not married at 
time of survey) and highest level of education (no school/ preschool, primary school, secondary school and above) attained by the mothers. Household socio-economic status was determined from the DHS wealth index. The DHS household wealth index is a standardized asset-based score that is divided into quintiles from one (lowest) to five (highest) [34]. Additional household variables included household residence (urban/rural) and household size (total number of people who usually lived in the household).

\section{Health utilization/behaviour factors}

Health utilization/behaviour factors included number of prenatal care visits (PNC) and child's immunization status, receipt of vitamin A supplements and meal frequency. Mothers were asked to indicate the number of PNC visits made to a health care provider while pregnant with the respective child. The WHO recommends a minimum of four pre-natal care visits among pregnant women and a cut-off of at least four visits was used to identify mothers with adequate PNC visits [35]. Information on immunization

Table 1 Health and socio-economic characteristics among children 6-24 months ${ }^{1}$

\begin{tabular}{|c|c|c|c|c|c|c|}
\hline & \multicolumn{2}{|l|}{ Kenya } & \multicolumn{2}{|l|}{ Uganda } & \multicolumn{2}{|l|}{ Tanzania } \\
\hline & Estimate & SE & Estimate & SE & Estimate & SE \\
\hline Children's age, mo (mean) & 14.19 & 0.20 & 14.66 & 0.23 & 14.29 & 0.13 \\
\hline \multicolumn{7}{|l|}{ Age category, mo (\%) } \\
\hline $6-8 \mathrm{mo}$ & 19.55 & 1.25 & 17.48 & 1.61 & 16.73 & 0.97 \\
\hline $9-11 \mathrm{mo}$ & 16.45 & 1.29 & 16.12 & 1.57 & 17.63 & 1.09 \\
\hline $12-17 \mathrm{mo}$ & 31.94 & 1.56 & 31.36 & 1.87 & 33.87 & 1.24 \\
\hline $18-24 \mathrm{mo}$ & 32.07 & 1.66 & 35.04 & 2.09 & 31.77 & 1.09 \\
\hline Birth order (mean) & 3.47 & 0.09 & 4.32 & 0.12 & 3.70 & 0.06 \\
\hline Child's sex: male (\%) & 51.39 & 1.59 & 47.48 & 2.14 & 48.91 & 1.25 \\
\hline Breast-feeding (\%) & 81.68 & 1.31 & 76.68 & 1.83 & 84.24 & 1.00 \\
\hline Diarrhea (\%) & 29.00 & 1.69 & 39.27 & 2.08 & 23.31 & 1.26 \\
\hline Cough (\%) & 32.01 & 2.04 & 54.10 & 2.27 & 27.59 & 1.33 \\
\hline Household head sex: male (\%) & 72.97 & 1.67 & 76.99 & 1.99 & 83.02 & 0.99 \\
\hline Mother married (\%) & 83.92 & 1.46 & 87.09 & 1.53 & 84.66 & 0.97 \\
\hline \multicolumn{7}{|l|}{ Mother's education (\%) } \\
\hline Preschool/none & 11.99 & 1.67 & 11.23 & 1.25 & 25.16 & 1.56 \\
\hline Primary school & 63.66 & 2.06 & 66.89 & 2.05 & 67.14 & 1.50 \\
\hline At least secondary school & 24.34 & 1.83 & 21.87 & 1.85 & 7.70 & 0.79 \\
\hline Working mother (\%) & 57.11 & 1.99 & 73.93 & 2.30 & 86.83 & 0.90 \\
\hline \multicolumn{7}{|l|}{ Wealth Index (\%) } \\
\hline First quintile & 22.87 & 1.88 & 22.49 & 1.99 & 22.19 & 1.32 \\
\hline Second quintile & 20.76 & 1.66 & 21.86 & 1.87 & 24.00 & 1.22 \\
\hline Third quintile & 18.20 & 1.65 & 20.48 & 1.77 & 20.67 & 1.17 \\
\hline Fourth quintile & 18.38 & 1.94 & 18.91 & 1.76 & 18.05 & 1.46 \\
\hline Fifth quintile & 19.78 & 2.72 & 16.26 & 1.55 & 15.09 & 1.33 \\
\hline Mother's age, years (mean) & 27.18 & 0.22 & 28.05 & 0.30 & 27.97 & 0.18 \\
\hline Household size (mean) & 5.95 & 0.14 & 6.15 & 0.13 & 6.96 & 0.18 \\
\hline Urban residence (\%) & 20.41 & 2.11 & 12.38 & 1.54 & 20.37 & 1.40 \\
\hline Prenatal care visits (mean) & 3.58 & 0.08 & 3.59 & 0.08 & 6.97 & 0.18 \\
\hline At least 4 PNC visits (\%) & 47.11 & 2.00 & 48.62 & 2.32 & 42.29 & 1.36 \\
\hline Immunization (\%) & 49.49 & 2.04 & 32.55 & 2.31 & 43.46 & 1.62 \\
\hline Received vitamin A (\%) & 73.89 & 1.74 & 63.19 & 2.19 & 66.32 & 1.46 \\
\hline Used modern contraceptives (\%) & 36.19 & 1.71 & 27.22 & 2.01 & 28.39 & 1.29 \\
\hline Minimum meal frequency (\%) & 67.31 & 2.13 & 39.59 & 2.26 & 34.83 & 1.41 \\
\hline
\end{tabular}


coverage was collected from children's health records and respondents' reports. Specific vaccines included Bacillus Calmette-Guérin (BCG), birth polio, polio I-III, diphtheria-pertussis-tetanus (DPT) I-III, and measles vaccine. An indicator of completion of age-specific immunization was created based on the recommended immunization schedule for infants in developing countries [36]. Information on Hepatitis B vaccination was not available. Information on receipt of vitamin A supplements was collected from children's health records. The WHO recommends that, in settings where vitamin A deficiency is a public health problem, children 6-11 months should receive one dose of 100,000 IU (30 mg RE) vitamin A, while children 12-59 months should receive 100,000 IU (30 mg RE) vitamin A, every 4-6 months [37].

Mothers were asked to indicate the number of times, in the previous day and night, a child had received anything to eat, aside from breast-milk, including meals and snacks. The WHO's minimum meal frequency definitions were applied [29]. Frequencies of consumption of solid, semi-solid and soft foods (including milk feeds for non-breastfed children) were calculated. For children who were still breast-feeding at the time of the surveys, minimum frequency was defined as 2 times for infants 6-8 months and 3 times for children 9-24 months [29]. For children who had stopped breast-feeding by the time of the surveys, minimum frequency was defined as 4 times for children 6-24 months [29].

\section{Statistical analysis}

A total of 5338, 2109 and 6957 children, 0-60 months old, were included in the Kenya, Uganda and Tanzania surveys respectively. Our analysis focused on children ages 6-23 months (1700, 707, 2276 children in Kenya,

Table 2 Meal frequency, food group consumption and DDS across children's ages

\begin{tabular}{|c|c|c|c|c|c|c|}
\hline \multirow[t]{2}{*}{ Intake indicator } & \multirow[t]{2}{*}{ Country } & \multicolumn{5}{|c|}{ Age of child (months) } \\
\hline & & $6-8$ & $9-11$ & $12-17$ & $18-23$ & $6-23$ \\
\hline \multirow[t]{3}{*}{ Minimum meal frequency (\%) } & Kenya & 74.86 & 67.74 & 65.39 & 64.15 & 67.31 \\
\hline & Uganda $^{*}$ & 55.77 & 33.87 & 42.91 & 30.43 & 39.59 \\
\hline & Tanzania ${ }^{*}$ & 63.33 & 25.40 & 31.46 & 28.38 & 34.83 \\
\hline \multirow[t]{3}{*}{ Cereals and tubers (\%) } & Kenya* & 55.26 & 75.83 & 76.69 & 79.93 & 73.40 \\
\hline & Uganda $^{*}$ & 65.04 & 88.56 & 89.75 & 88.45 & 84.78 \\
\hline & Tanzania ${ }^{*}$ & 83.29 & 92.82 & 93.06 & 94.47 & 91.84 \\
\hline \multirow[t]{3}{*}{ VAFVs (\%) } & Kenya* & 31.64 & 50.03 & 41.46 & 47.48 & 42.88 \\
\hline & Uganda & 13.48 & 18.47 & 18.02 & 25.71 & 19.99 \\
\hline & Tanzania ${ }^{*}$ & 22.59 & 32.33 & 33.04 & 37.38 & 32.55 \\
\hline \multirow[t]{3}{*}{ OFVs (\%) } & Kenya $^{*}$ & 46.40 & 62.05 & 73.05 & 75.57 & 66.83 \\
\hline & Uganda* & 28.59 & 51.32 & 56.73 & 51.33 & 49.05 \\
\hline & Tanzania ${ }^{*}$ & 44.08 & 62.18 & 67.84 & 65.90 & 62.25 \\
\hline \multirow[t]{3}{*}{ Dairy (\%) } & Kenya & 58.99 & 66.93 & 58.18 & 52.50 & 57.96 \\
\hline & Uganda & 26.74 & 33.76 & 24.93 & 29.51 & 28.27 \\
\hline & Tanzania & 25.99 & 30.55 & 31.40 & 31.36 & 30.34 \\
\hline \multirow[t]{3}{*}{ Legumes (\%) } & Kenya* & 15.19 & 28.52 & 29.26 & 33.62 & 27.79 \\
\hline & Uganda* & 40.14 & 65.43 & 57.54 & 58.04 & 55.95 \\
\hline & Tanzania $^{*}$ & 28.17 & 36.76 & 41.83 & 42.83 & 38.97 \\
\hline \multirow[t]{3}{*}{ MFPEs (\%) } & Kenya* & 13.39 & 18.65 & 29.47 & 34.58 & 26.19 \\
\hline & Uganda* & 22.84 & 40.05 & 32.80 & 39.71 & 34.65 \\
\hline & Tanzania ${ }^{*}$ & 22.59 & 33.59 & 40.79 & 44.15 & 37.54 \\
\hline \multirow[t]{3}{*}{ DDS < $1(\%)$} & Kenya* & 14.66 & 4.76 & 5.26 & 7.62 & 7.77 \\
\hline & Uganda* & 15.03 & 1.51 & 4.69 & 7.39 & 6.93 \\
\hline & Tanzania* & 11.15 & 1.93 & 2.39 & 3.11 & 4.01 \\
\hline \multirow[t]{3}{*}{ DDS $\geq 4(\%)$} & Kenya $^{*}$ & 22.52 & 39.22 & 39.50 & 48.63 & 39.06 \\
\hline & Uganda* & 15.45 & 32.09 & 28.73 & 36.00 & 29.50 \\
\hline & Tanzania ${ }^{*}$ & 18.02 & 30.81 & 34.84 & 38.80 & 32.58 \\
\hline
\end{tabular}

"Statistically significant differences between age groups. 
Uganda, Tanzania respectively). A decision was made to include only the youngest child within this age-group from each household. This resulted in 1668 children in Kenya; 701 children in Uganda and 2247 children in Tanzania with dietary diversity data. SAS Version 9.2 (SAS Institute, Cary, NC, USA) was used for data analysis. Survey analysis procedures were appropriate for the DHS complex study design and utilized to help estimate sampling errors. SAS procedures surveyfreq, surveymeans, surveyreg and surveylogistic were used to estimate means, percentages, and odds ratios. Logistic regression analysis was used to assess the odds of achieving adequate DDS. Bivariate logistic regression was used to assess the association between each independent variable (Table 1) and our outcome variable, adequate DDS (DDS $\geq 4$ ). Thereafter, only independent variables that showed a significant association with adequate DDS, in the bivariate analysis, were simultaneously entered into a multivariate logistic regression model. Nonresponse across variables reduced the effective sample size in the multivariate regression to 1588 in Kenya, 674 in Uganda and 2185 in Tanzania (4.80, 3.85 and 2.76 percent loss in sample size, respectively).

\section{Results}

Table 1 gives a summary of the children's social-economic, health, and health care utilization characteristics for each of the three countries. Children's mean ages were below 15 months, and the mean birth order was at about four across all three countries. Approximately $50 \%$ of children were males. Approximately $80 \%$ of the children were still breast-feeding at the time of the respective surveys. Highest diarrhea and cough prevalence were reported in Uganda. Mean mother's age was at about 28 years for all three countries. A majority of mothers had primary school

Prevalence of VAFV in take in Kenya, Uganda and Tanzania

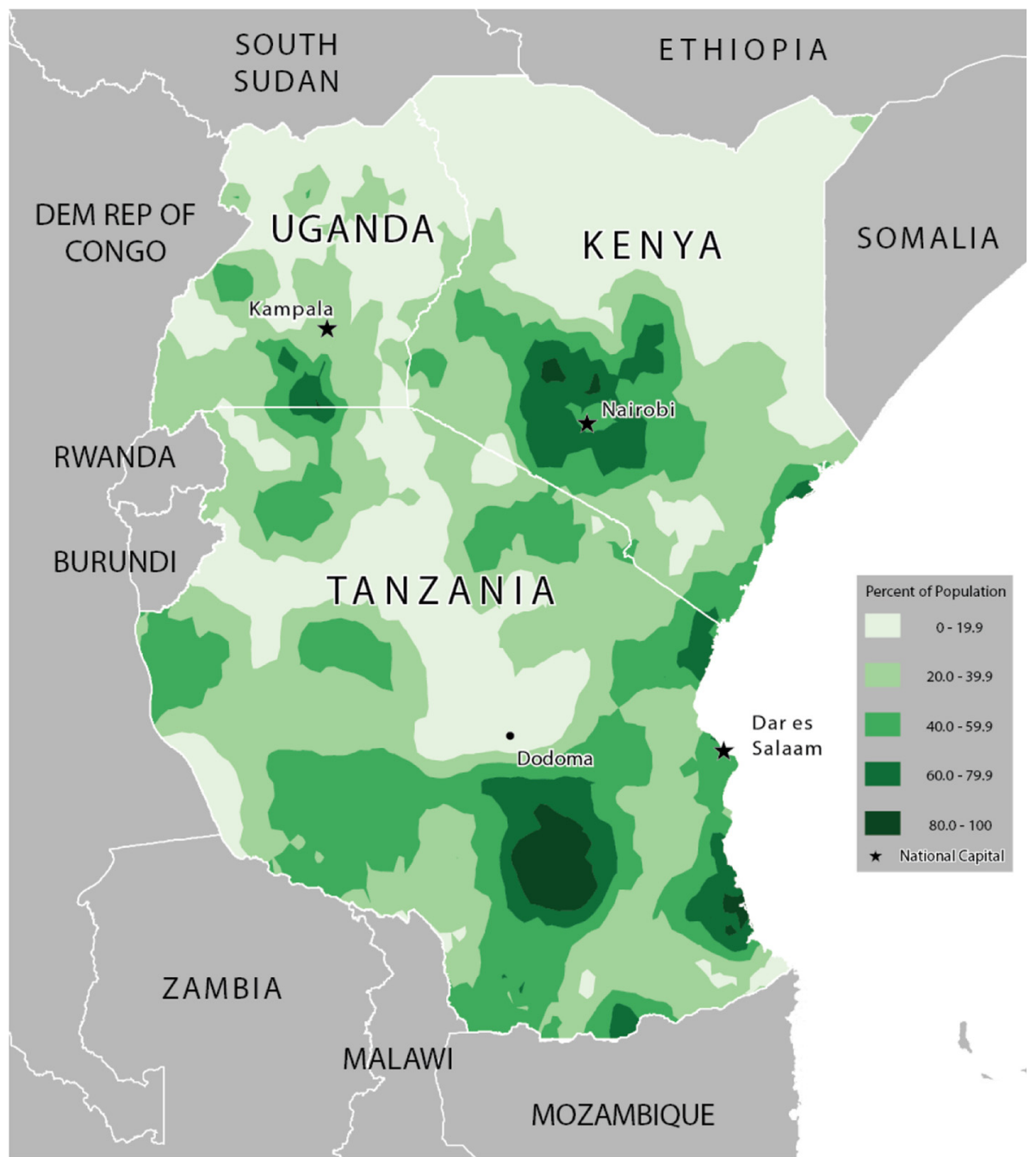

Figure 2 Prevalence of VAFV intake in Kenya, Uganda and Tanzania. 
level education and were working. A majority of the households were headed by males and were located in rural areas. The mean household size ranged from about six to seven household members across all countries. Mothers had made an average of three PNCs. Use of modern contraceptives was below $40 \%$ in each country. Up-to-date immunization coverage was below $50 \%$ in each country. Over $60 \%$ of children had received vitamin A supplements.

\section{Intake prevalence and geographic distribution}

Table 2 shows the food consumption rate across agegroups and for all children. Figures 2, 3, 4, 5, 6 and 7 provide geographic representations of food group consumption rates across Kenya, Uganda and Tanzania. The percentage of children with adequate meal frequencies was higher in Kenya than in Uganda and Tanzania. The percent of children with minimum meal frequency decreased with age with the largest drop noted between the 6-8 month and 9-11 month age groups.

In Kenya, cereals-tubers were commonly consumed while consumption of legumes and MFPEs was lacking (Figures 4 and 6 ). High consumption rate ( $>60 \%$ of population) of VAFVs, OFVs and dairy foods was localized only to the central highlands of Kenya (Figure 2, 3 and 5). The DDS scores in Kenya showed a clear geographic partition with the highest scores observed around Nairobi and central regions (Figure 7). Score values decreased as one moved away from the central regions. An exception to this was found at the northeastern border tip which reported a mean DDS score within the 3-3.49 range (Figure 7).

With the exception of VAFVs and dairy foods (Figures 2 and 4), Uganda seemed to have fared better with a more balanced and spread-out intake of OFVs and legumes and

Prevalence of OFV intake in Kenya, Uganda and Tanzania

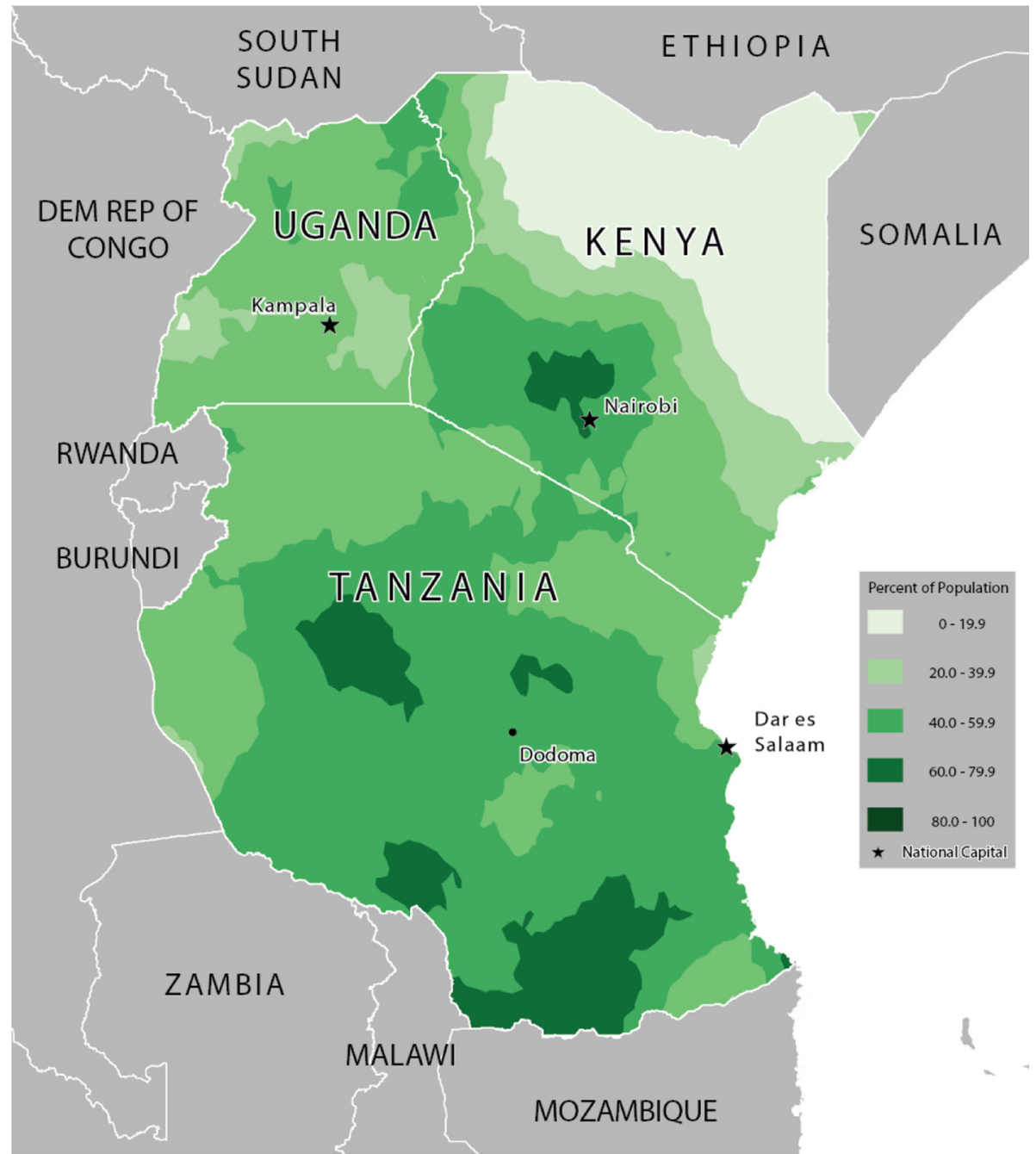

Figure 3 Prevalence of OFV intake in Kenya, Uganda and Tanzania. 


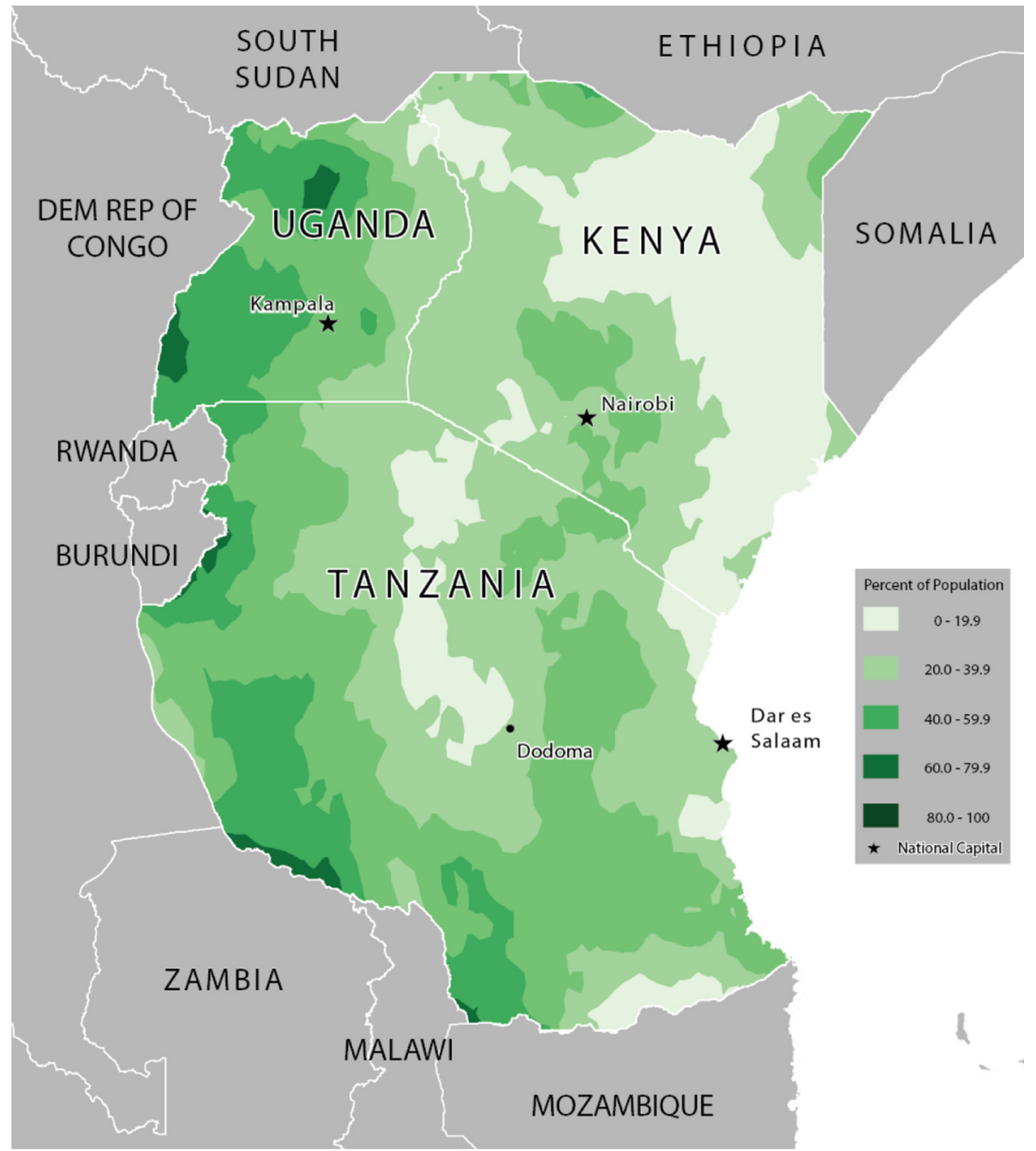

Figure 4 Prevalence of legume intake in Kenya, Uganda and Tanzania.

to a certain extent MFPEs (Figures 3, 5 and 6). Uganda had fairly consistent DDS across the country with the highest DDS $(\geq 3.50)$ noted around Rakai district (Figure 7).

With the exception of cereals-tubers, less than $40 \%$ of children in Tanzania had consumed foods from the remaining five food groups in the last 24 hours (Table 2). Consumption of dairy foods, VAFVs, legumes/nuts, and MFPEs in Tanzania was localized to a few specific locations within the country (Figures 2, 3, 4, 5 and 6). However, consumption of OFVs was more balanced across the country. Tanzania had fairly consistent DDS, with a pocket of low values in the central parts. The highest DDS values were noted along Tanzania's borders with Kenya, Zambia, and Mozambique (Figure 7).

Mean DDS were below three across all countries: $2.95 \pm$ 0.07 in Kenya, $2.73 \pm 0.06$ in Uganda, and $2.93 \pm 0.04$ in
Tanzania. Kenya reported the highest percentage of children who had adequate DDS (Table 2). Tanzania reported the lowest percentage of children who had not consumed any foods from the six food groups. Food group consumption rates were significantly different across children's age groups. With the exception of dairies, there was a distinct bump in consumption rate from the youngest children (6-8 months old) to those within the $9-11$ month age-group, after which consumption rates remained relatively stable.

\section{Prediction complementary food diversity Child factors}

Being an older child (9-11, 12-17 \& 18-24 months) was associated with significantly higher odds of achieving adequate DDS compared to those within the 6-8 month age-group across all three countries: 125\%-299\% higher 


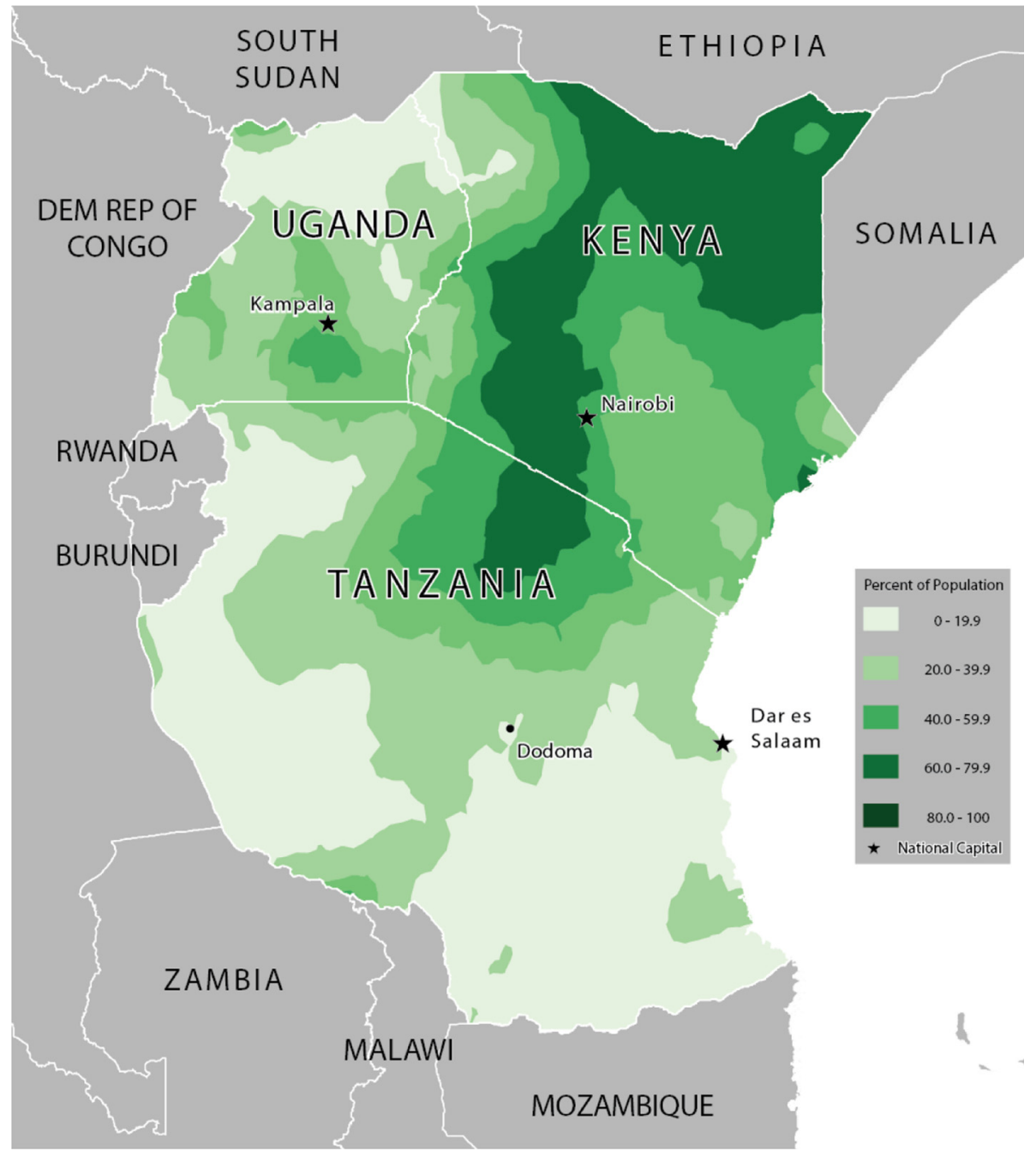

Figure 5 Prevalence of dairy food intake in Kenya, Uganda and Tanzania.

for the 9-11 month age-group, $164 \%-174 \%$ higher for the 12-17 month age-group, and 219\%-300\% higher for the 18-24 month age-group (Table 3). In Uganda, children who were breast-feeding at the time of the survey were associated with $63 \%$ reduction in odds of achieving adequate DDS compared to those who were not breast-feeding.

\section{Socio-economic and demographic factors}

Mothers' working status was shown to be a significant factor only in Kenya, where children whose mothers were working at the time of survey were associated with $47 \%$ increase in odds of achieving adequate DDS compared to those with non-working mothers. Children living in households within higher wealth index quintiles were associated with significantly higher odds of achieving adequate DDS compared to those living in households within the first wealth index quintile. However, the relationship was not uniform across all countries. In Kenya, significance was shown among households in the second, fourth and fifth wealth index quintiles. In Uganda, the relationship was noted among households in the fifth quintile. In Tanzania, the relationship was noted among households in third, fourth and fifth quintiles (Table 3).

\section{Health utilization/behaviour factors}

In Kenya, children whose mothers had made at least four PNCs were associated with 105\% increase in odds of achieving adequate DDS compared to children whose mothers did not. In Tanzania, children who had received vitamin A supplements were associated with $43 \%$ increase in odds of achieving DDS compared to those had not. In 


\section{Prevalence of MFPE intake in Kenya, Uganda and Tanzania}

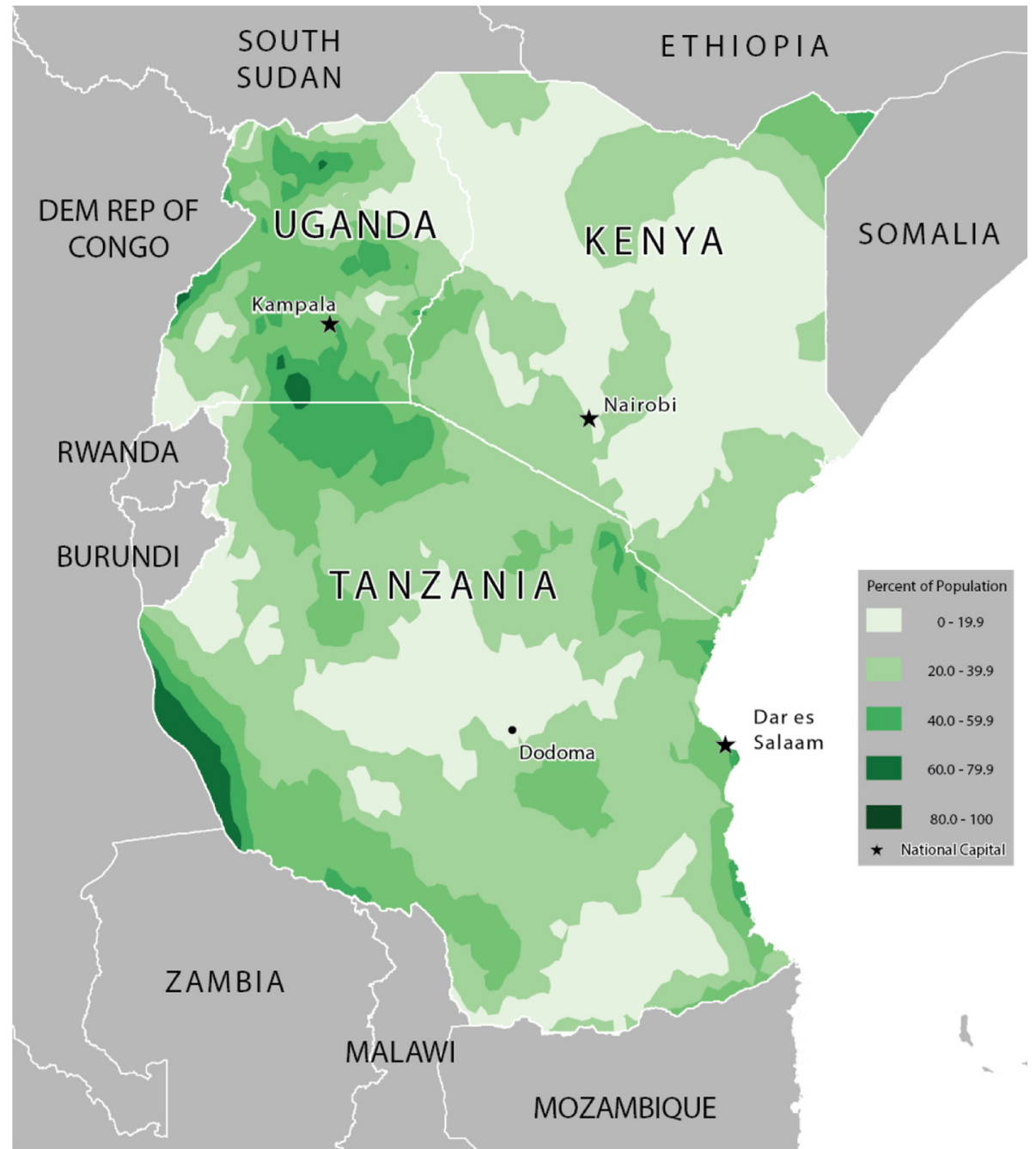

Figure 6 Prevalence of MFPE intake in Kenya, Uganda and Tanzania.

Tanzania, children whose mothers utilized modern contraceptive methods were associated with $40 \%$ increase in odds of achieving adequate DDS compared to children whose mothers did not. Children who had consumed at least the defined minimum number of meals per day were associated with 153\%, 213\% and 51\% increase in odds of achieving adequate DDS in Kenya, Uganda and Tanzania respectively (Table 3 ).

In a combined analysis that included all three countries, being an older child, mother's post-primary education, higher household wealth, at least four prenatal care visits, use of modern contraceptives, and daily consumptions at or above the minimum meal frequency adequate meal frequencies were each associated with significantly higher odds of achieving adequate DDS among young children in the East African region (Table 3).

\section{Discussion}

On average, young children's diets in Kenya, Uganda and Tanzania consisted of foods from two food groups. Cereals and tubers have been shown to be the most common weaning food across sub-Sahara Africa [38-40]. The reported DDS means and percentages were considerably low when compared to consumption rates outside subSahara Africa $[7,41]$. We would like to note that although the overall diet diversity scores reported in the current analysis are similar to those reported among populations in West, Central and South African regions, diet composition is expected to differ across regions [38-40]. For example, fish has been shown to be a common part of the diet in countries along the West African coastline, making MFPEs a major contributor to young children's diet in that region $[39,40]$. 
Distribution of mean DDS in Kenya, Uganda and Tanzania

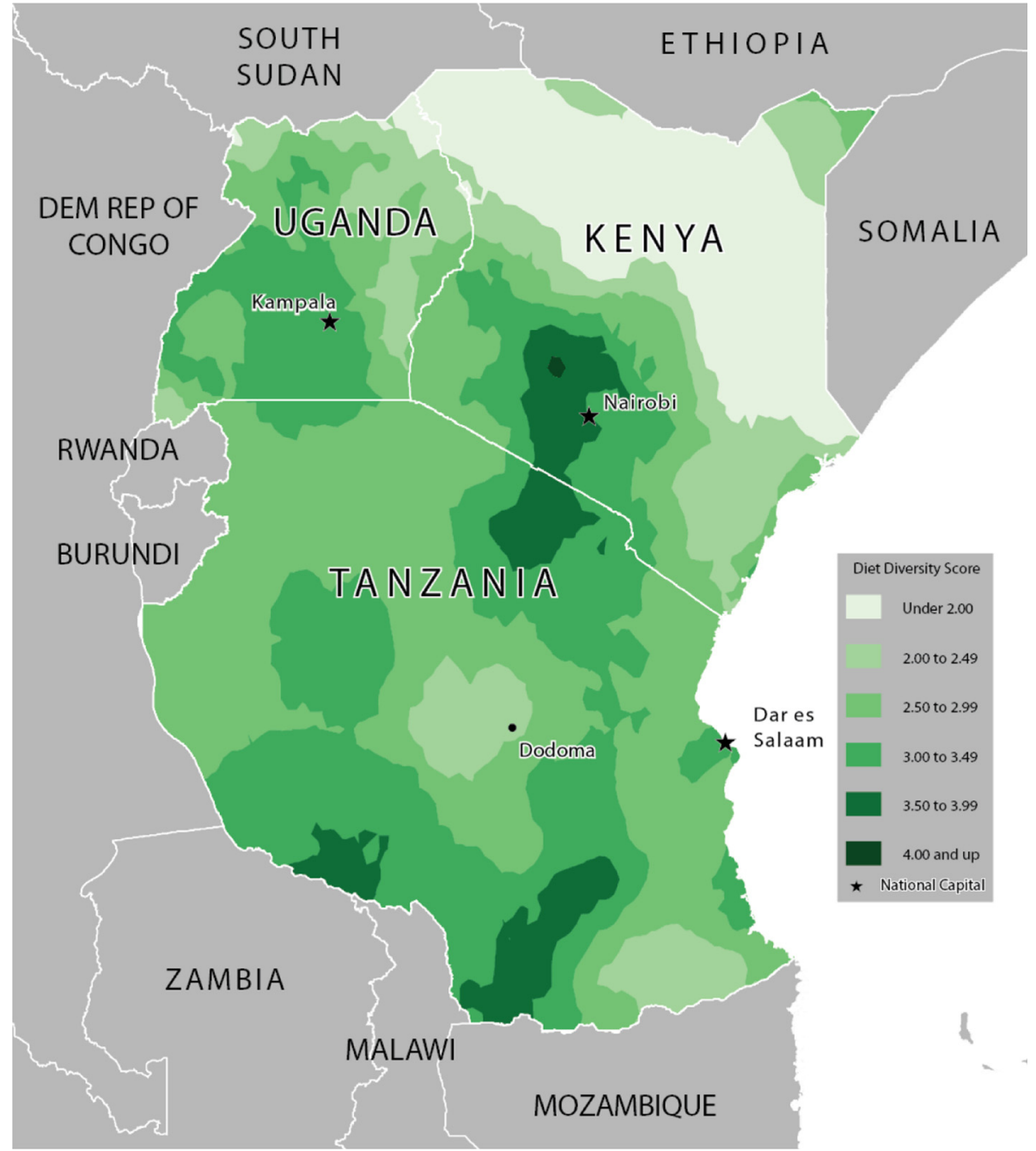

Figure 7 Distribution of mean DDS in Kenya, Uganda and Tanzania.

Despite having lower mean DDS scores than Kenya, Uganda experienced a more balanced DDS distribution compared to Kenya. Over the years, Uganda has experienced an overall increase in the production of some of its major agricultural products including maize, rice and sorghum, beans, groundnuts, sesame, milk and beef [42]. However, the increased milk production did not translate to increased prevalence of consumption for this group of children. Overall, VAFVs were the least commonly consumed foods in Uganda, despite the previous promotion of orange-fleshed sweet potato as an affordable source of vitamin A in Uganda [43]. The low VAFV consumption levels may be due to the reported decline in sweet potato production in Uganda [42].

Dietary diversity score geographic distribution in Kenya seems to match the agricultural production patterns in the country; highest around the central highlands and lowest in the northern and north-eastern part of the country. An assessment of agricultural production estimates showed that the amount of maize, wheat and bean produced declined between 2003-2008 while production of red meats increased over the same period [44]. However, a large proportion of the meats consumed in Kenyan homes come from commercial sources, which tend to be quite expensive and inaccessible to those who may need them the most [34]. Among the pastoralists in the arid and semi-arid parts of Kenya, cattle are considered status symbols that help support wealth generation and maintain one's social status and are not regularly slaughtered for home consumption. This may help explain the high consumption of dairy foods coupled with a general lack of MFPE consumption in that region.

The geographic dietary diversity score distribution in Tanzania also appears to match agricultural production 
Table 3 Predictors of adequate diet diversity (DDS $\geq 4$ ) among children 6-23 months ${ }^{1}$

\begin{tabular}{|c|c|c|c|c|c|c|c|c|}
\hline & \multicolumn{2}{|c|}{ Kenya } & \multicolumn{2}{|c|}{ Uganda } & \multicolumn{2}{|c|}{ Tanzania } & \multicolumn{2}{|c|}{ All countries } \\
\hline & $\mathrm{aOR}$ & $95 \% \mathrm{Cl}$ & $\mathrm{aOR}$ & $95 \% \mathrm{Cl}$ & $\mathrm{aOR}$ & $95 \% \mathrm{Cl}$ & $\mathrm{aOR}$ & $95 \% \mathrm{Cl}$ \\
\hline \multicolumn{9}{|l|}{ Age category, (ref., 6 - 8 mo) } \\
\hline $9-11 \mathrm{mo}$ & $2.57^{*}$ & $1.47,4.49$ & $3.99^{*}$ & $1.81,8.77$ & $2.25^{*}$ & $1.40,3.62$ & $2.61^{*}$ & $1.87,3.65$ \\
\hline $12-17 \mathrm{mo}$ & $2.65^{*}$ & $1.67,4.19$ & $2.74^{*}$ & $1.31,5.73$ & $2.64^{*}$ & $1.75,3.98$ & $2.75^{*}$ & $2.07,3.63$ \\
\hline $18-24 \mathrm{mo}$ & $4.00^{*}$ & $2.24,7.15$ & $3.45^{*}$ & $1.63,7.30$ & $3.19^{*}$ & $2.06,4.94$ & $3.61^{*}$ & $2.63,4.96$ \\
\hline Birth order & 0.95 & $0.87,1.02$ & - & - & 0.99 & $0.94,1.04$ & 0.99 & $0.95,1.02$ \\
\hline Breast-feeding, (ref., no) & 0.95 & $0.66,1.38$ & $0.38^{*}$ & $0.22,0.65$ & 0.92 & $0.66,1.38$ & 0.85 & $0.67,1.07$ \\
\hline Cough, (ref., no) & - & - & - & - & 1.26 & $0.98,1.62$ & - & - \\
\hline \multicolumn{9}{|l|}{ Education (ref., preschool/none) } \\
\hline Primary school & 1.59 & $0.84,3.00$ & 1.59 & $0.76,3.31$ & 1.08 & $0.77,1.52$ & 1.22 & $0.92,1.62$ \\
\hline At least secondary school & 1.81 & $0.90,3.66$ & 2.10 & $0.87,5.08$ & 1.33 & $0.77,2.30$ & $1.54^{*}$ & $1.10,2.18$ \\
\hline Working mother (ref., no) & $1.47^{*}$ & $1.03,2.12$ & - & - & - & - & - & - \\
\hline \multicolumn{9}{|l|}{ Wealth Index (ref., first quintile) } \\
\hline Second quintile & $1.72^{*}$ & $1.07,2.75$ & 0.64 & $0.32,1.25$ & 1.34 & $0.94,1.91$ & $1.37^{*}$ & $1.06,1.76$ \\
\hline Third quintile & 1.64 & $0.98,2.75$ & 1.13 & $0.62,2.05$ & $2.02^{*}$ & $1.40,2.91$ & $1.81^{*}$ & $1.38,2.37$ \\
\hline Fourth quintile & $2.43^{*}$ & $1.46,4.01$ & 1.44 & $0.72,2.89$ & $2.47^{*}$ & $1.61,3.78$ & $2.38^{*}$ & $1.78,3.18$ \\
\hline Fifth quintile & $1.89^{*}$ & $1.05,3.42$ & $3.05^{*}$ & $1.37,6.83$ & $4.24^{*}$ & $2.58,6.95$ & $3.27^{*}$ & $2.28,4.67$ \\
\hline 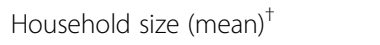 & 0.98 & $0.92,1.04$ & _ & _- & _- & _- & 0.99 & $0.95,1.03$ \\
\hline Rural residence (ref., urban) & 0.57 & $0.31,1.04$ & 1.04 & $0.51,2.11$ & 1.10 & $0.77,1.56$ & 0.88 & $0.65,1.19$ \\
\hline At least 4 PNC visits (ref., no) & $2.05^{*}$ & $1.48,2.85$ & - & - & 1.06 & $0.85,1.31$ & $1.25^{*}$ & $1.05,1.50$ \\
\hline Immunized (ref., no) & 0.96 & $0.69,1.32$ & 1.21 & $0.79,1.85$ & 0.98 & $0.78,1.23$ & 1.01 & $0.85,1.20$ \\
\hline Received vitamin A (ref., no) & - & - & - & - & $1.43^{*}$ & $1.11,1.84$ & 1.12 & $0.92,1.35$ \\
\hline Modern contraceptives (ref., no) & 1.31 & $0.92,1.86$ & - & - & $1.40^{*}$ & $1.10,1.79$ & $1.35^{*}$ & $1.12,1.62$ \\
\hline Min. feeding frequency (ref., no) & $2.54^{*}$ & $1.80,3.58$ & $3.13^{*}$ & $2.06,4.77$ & $1.51^{*}$ & $1.21,1.89$ & $1.98^{*}$ & $1.67,2.34$ \\
\hline
\end{tabular}

aOR: adjusted odds ratio; SE: standard error; mo: month; min: minimum; PNC: prenatal care.

${ }^{*}$ aOR estimates were statistically significant $(p<0.05),{ }^{\dagger}$ OR values computed for one additional household member.

patterns in the country. A recent report on food crop production in Tanzania showed that starchy foods like cassava, bananas, potatoes and maize were more common and contributed to $82 \%$ of the food crops produced over a 10 year period (1998-2008) [45]. According to the report, legumes contributed to only $5 \%$ of food crop production, 40 to $60 \%$ of the fruits and vegetables produced was lost at post-harvest and meat production from smaller animals made up less than half of the beef produced in the country [45].

Our analysis showed that consumption of foods from multiple food groups increased with age. Previous studies have documented a similar increase across age $[39,40,46]$. Between $70-97 \%$ of the recommended iron, zinc, phosphorous, magnesium, sodium and calcium intakes among 9-11 month old children need to be supplied by complementary foods [10]. Increasing dietary diversity is associated with a higher likelihood of meeting children's recommended nutrient intake levels [32]. The negative relationship between breast-feeding and adequate DDS, amongst Ugandan children, has been reported in other countries and has notable implications for IYCF promotion efforts [47]. Although a majority of children within the 6-17 month age group were still breast-feeding at the time of survey, it is possible that their mothers were not aware of the importance of adequate dietary diversity in meeting young children's nutritional needs. Although breast-milk can make a major contribution to the total nutrient intake of children within 6-24 months of age, breast-milk may not be an adequate source of micronutrients such as iron, zinc and vitamin $\mathrm{A}$, as children become older, and especially in the presence of maternal deficiency $[48,49]$.

Indicators of socio-economic status (household wealth, maternal education and a working mother) were shown to have a positive relationship with adequate DDS. Higher economic status is associated with improved access to informational, financial, and material resources. Dose-response relationships between household wealth and young children's DDS, similar to that noted in Tanzania, has been reported in other countries $[41,50]$. Pre-natal care, immunization, and provision of vitamin 
A supplements and modern contraceptives are often offered as part of preventive care management, and caregivers have to make a conscious and informed effort to utilize them. The positive relationship between PNC visits and adequate DDS is similar to findings from India [47]. Our analysis controlled for household wealth, thus suggesting that the relationship between the use of these services and DDS goes beyond the issue of affordability. Mothers who utilized these services may be more motivated to take better care of their children. It is also likely that mothers who used these services were exposed to nutrition and health education messages. Previous research has shown that complementary feeding education among mothers was associated with higher intakes of cereals, legumes, milk, vegetables and fruits and better growth $[9,51,52]$. The positive relationship between meal frequencies and adequate DDS reinforces the WHO's recommendation on complementary feeding [29]. The WHO's meal frequency recommendations were based on children's energy needs and gastric capacity which limits the food volume in one meal [29]. Thus, complementary food meal frequency should be addressed in nutrition education messages.

\section{Conclusions}

Though limited by its use of one day of dietary data, our analysis has identified specific characteristics and factors that would be useful in targeting and promoting IYCN in the East African region. Inadequate complementary food diversity in all three countries, low meal frequency in Uganda and Tanzania, and to some extent delayed introduction of complementary feeding in Kenya and Uganda are of concern. We hope that results from this analysis will encourage cross-sector and cross-country collaboration to help identify specific policies and practices associated with the improving complementary food quality in all parts of the region. Adoption of nutritionfriendly health, agricultural and marketing policies that help break barriers, support increased availability and access to nutrient dense foods and expand nutrition education opportunities would help meet set IYCN goals.

\footnotetext{
Abbreviations

BCG: Bacillus Calmette-Guérin; DDS: Complementary food diversity score; DHS: Demographic Health Survey; DPT: Diphtheria-pertussis-tetanus; FMOH: Federal Ministry of Health; IYCF: Infant and young child feeding; IYCN: Infant and young child nutrition; MFP: Meats/fish and poultry; MFPEs: Meats/fish/poultry/eggs; OFV: Other fruits and vegetables; PNC: Prenatal care; VAFV: Vitamin A-rich fruits and vegetables; WHO: World Health Organization.
}

\section{Competing interests}

The authors declare that they have no competing interests.

\section{Authors' contributions}

CAG and TFL contextualized the analysis; TFL was responsible for the cartographic analysis; CAG was responsible for the statistical analysis; both co-authors were responsible for the writing of the manuscript and read and approved the final manuscript.

\section{Author details}

'Department of Nutrition and Food Studies, George Mason University, 4400 University Dr. MSN 1F8, Fairfax, VA 22030, USA. ²Department of Geography and Geoinformation Science, George Mason University, 4400 University Dr. MSN 6C3, Fairfax, VA 22030, USA.

Received: 12 March 2013 Accepted: 29 September 2014

Published online: 01 May 2015

\section{References}

1. Black RE, Allen LH, Bhutta ZA, Caulfield LE, de Onis M, Ezzati M, et al. Maternal and child undernutrition: global and regional exposures and health consequences. Lancet. 2008;371(9608):243-60.

2. Mitchell M. Nutrition across the lifespan. 2nd ed. Long Grove Illinois: Waveland Press Inc.; 2008. p. 209-339.

3. Kramer MS, Kakuma R. Optimal duration of exclusive breastfeeding. Cochrane Database of Systematic Reviews [Internet]. John Wiley \& Sons, Ltd; 1996. Available from: http://onlinelibrary.wiley.com/doi/10.1002/ 14651858.CD003517.pub2/abstract.

4. United Nations Children's Fund. WHO/UNAIDS/UNICEF infant feeding guidelines [Internet]. UNICEF; 2005. Available from: http://www.unicef.org/ nutrition/index_24811.html.

5. WHO. HIV and infant feeding: principles and recommendations for infant feeding in the context of HIV and summary of evidence [Internet]. WHO; 2010. Available from: http://whqlibdoc.who.int/publications/2010/ 9789241599535_eng.pdf

6. Onyango A, Koski KG, Tucker KL. Food diversity versus breastfeeding choice in determining anthropometric status in rural Kenyan toddlers. Int J Epidemiol. 1998;27(3):484-9.

7. Arimond M, Ruel MT. Dietary diversity, dietary quality, and child nutritional Status: evidence from eleven demographic and health surveys. Washington, DC: FANTA Project III; 2004

8. Sawadogo PS, Martin-Prével Y, Savy M, Kameli Y, Traissac P, Traoré AS, et al. An infant and child feeding index is associated with the nutritional status of 6-to 23-month-old children in rural Burkina Faso. J Nutr. 2006;136(3):656-63.

9. Imdad A, Yakoob MY, Bhutta ZA. Impact of maternal education about complementary feeding and provision of complementary foods on child growth in developing countries. BMC Public Health. 2011;11 Suppl 3:S25.

10. Dewey K. Guiding principles for complementary feeding of the breastfed child [Internet]. PAHO; 2003. Available from: http://whqlibdoc.who.int/paho/ 2003/a85622.pdf?ua=1.

11. Measure DHS. Demographic Health Surveys [Internet]. Available from: http:// www.measuredhs.com/.

12. UNICEF. State of the world's children 2012: children in an urban world [Internet]. UNICEF; 2012. Available from:http://www.unicef.org/sowc2012/ pdfs/SOWC\%202012-Main\%20Report_EN_13Mar2012.pdf.

13. World Bank. The World Bank data: low income countries [Internet]. The World Bank data: low income countries. 2014. Available from: http:// data.worldbank.org/income-level/LIC.

14. East African Community [Internet]. Available from: http://www.eac.int/.

15. Measure DHS. Measure DHS Demographic Health Surveys [Internet]. Available from: http://www.measuredhs.com/publications/PublicationSearch.cfm.

16. Kenya: National strategy on infant and young child feeding: 2007 - 2010 [Internet]. Republic of Kenya. Ministry of Public Health and Sanitation, WHO \& UNICEF. Available from: http://www.hennet.or.ke/downloads/ Unicef\%20KCO-Young\%20Feeding\%20Infantr.pdf.

17. Uganda Food and Nutrition Policy [Internet]. The Republic of Uganda. Ministry of Agriculture, Animal Industry and Fisheries \& Ministry of Health; 2003 p. 14 - 17. Available from: https:/extranet.who.int/nutrition/gina/sites/ default/files/UGA\%202003\%20The\%20Uganda\%20Food\%20and\%20 Nutrition\%20Policy.pdf.

18. Policy guidelines on infant and young child feeding [Internet]. The Republic of Uganda. Ministry of Health; 2009. Available from: https:/extranet.who.int/ nutrition/gina/sites/default/files/UGA\%202009\%20IYCF\%20Guidelines.pdf.

19. Tanzania national strategy on infant and young child nutrition. Wizara ya Afya: Shirika la Chakula Bora. Tanzania Food and Nutrition Centre; 2004. 
20. The national roadmap strategic plan to accelerate reduction of maternal, newborn and child deaths in Tanzania: 2008-2015 [Internet]. United Republic of Tanzania. Ministry of Health and Social Welfare; 2008. Available from: http://www.basics.org/documents/pdf/National\%20Road\%20Map\%20 Strategic\%20plan.pdf.

21. Hunter DJ, Killoran A. Tackling health inequalities: turning policy into practice? [Internet]. The Health Development Agency; 2004. Available from: http://www.who.int/rpc/meetings/Hunter_Killoran_Report.pdf.

22. Ekesa B, Walingo M, Abukutsa-Onyango M. Influence of agricultural biodiversity on dietary diversity on preschool children in Matungu Division, Western Kenya. AJFAND. 2008;8(4):390-404.

23. Ngala S, Asare E, Mwangi A, Brouwer I. Comparison of dietary diversity and its association with nutritional status between women of childbearing age and non-breasting feeding Children (2-5 years) in rural Kenya [Internet]. Wageningen University. Available from: http://www.afrikastudies.nl/ downloads-conferences/Motherchild.pdf.

24. ICF International. Demographic and Health Survey: sampling and household listing manual [Internet]. Calverton, MD: ICF International; 2012. Available from: http://www.measuredhs.com/pubs/pdf/DHSM4/DHS6_Sampling_ Manual_Sept2012_DHSM4.pdf.

25. ICF International. Survey organization manual for demographic and health surveys. [Internet]. Calverton, MD: ICF International; 2012. Available from: http://www.measuredhs.com/publications/publication-dhsm10-dhsquestionnaires-and-manuals.cfm.

26. Gewa CA, Leslie TF, Pawloski LR. Geographic distribution and socio-economic determinants of women's nutritional status in Mali households. Public Health Nutr. 2013;16(9):1575-85.

27. Leslie TF, Frankenfeld CL, Makara MA. The spatial food environment of the DC metropolitan area: Clustering, co-location, and categorical differentiation. Appl Geogr. 2012;35(1-2):300-7.

28. Sakata S, Ashida F, Zako M. Structural optimization using Kriging approximation. Comput Methods Appl Mech Eng. 2003;192(7):923-39.

29. WHO. Indicators for assessing infant and young child feeding practices part 3-country profiles [Internet]. Geneva, Switzerland: World Health Organization; 2010. Available from: http://whqlibdoc.who.int/publications/2010/ 9789241599757_eng.pdf.

30. Steyn N, Nel J, Nantel G, Kennedy G, Labadarios D. Food variety and dietary diversity scores in children: are they good indicators of dietary adequacy? Public Health Nutr. 2007;9(5):644-50.

31. Kennedy GL, Pedro MR, Seghieri C, Nantel G, Brouwer I. Dietary diversity score is a useful indicator of micronutrient intake in non-breast-feeding Filipino children. J Nutr. 2007;137(2):472-7.

32. Moursi MM, Arimond M, Dewey KG, Treche S, Ruel MT, Delpeuch F. Dietary diversity is a good predictor of the micronutrient density of the diet of 6- to 23-month-old children in Madagascar. J Nutr. 2008;138(12):2448-53.

33. Dewey K, Arimond M, Ruel M. Working Group on Infant and Young Child Feeding Indicators. Developing and Validating Simple Indicators of Dietary Quality of Infants and Young Children in Developing Countries: Additional analysis of 10 data sets. [Internet]. Washington, DC: FANTA Project III; 2007. Available from: http://www.fantaproject.org/sites/default/files/resources/ IYCF_Datasets_2007.pdf.

34. Rustein SO, Johnson K. The DHS Wealth Index [Internet]. MD: Macro International; 2004. Report No.: 6. Available from: http://www.measuredhs. com/pubs/pdf/CR6/CR6.pdf.

35. Villar J, Bergsjo P. WHO antenatal care randomized trial: manual for the implementation of the new model. Geneva: WHO; 2002.

36. WHO. State of world's vaccines and immunizations. Geneva: World Health Organization; 2003.

37. WHO. Guideline: vitamin A supplementation in infants and children 6-59 months of age. Geneva, Switzerland: World Health Organization; 2011.

38. Maclntyre U, de Villiers F, Baloyi P. Early infant feeding practices of mothers attending a postnatal clinic in Ga-Rankuwa. SAJCN. 2005;18(2):70-5.

39. Ogunba BO. Diet diversity in complementary feeding and nutritional status of children aged 0 to 24 months in Osun State, Nigeria: a comparison of the urban and rural communities. ICAN. 2010;2(6):330-5.

40. Sawadogo SP, Yves M-P, Claire M-R, Alain B, Alfred TS, Serge T, et al. Late introduction and poor diversity were the main weaknesses of complementary foods in a cohort study in rural Burkina Faso. Nutrition [Internet]. 2010 Jul;26(7-8):746-52. Available from: http://search.proquest.com/ biologicalscience/docview/1130317130/abstract/D8BD1D57F992416APQ/ 1 ? accountid=14541.
41. Senarath U, Godakandage SSP, Jayawickrama H, Siriwardena I, Dibley MJ. Determinants of inappropriate complementary feeding practices in young children in Sri Lanka: secondary data analysis of Demographic and Health Survey 2006-2007. Matern Child Nutr. 2012;8 suppl 1:60-77.

42. Agriculture for Food and Income Security. Agricultural Sector Development Strategy and Investment Plan: 2010/11-2014/15 [Internet]. Republic of Uganda: Ministry of Agriculture, Animal Industries \& Fisheries; 2010. Available from: https://extranet.who.int/nutrition/gina/sites/default/files/ UGA\%202010\%20Agriculture\%20Sector\%20Development\%20Strategy\%20 and\%20lnvestment\%20Plan.pdf.

43. Hotz C, Loechl C, Lubowa A, Tumwine JK, Ndeezi G, Nandutu Masawi A, et al. Introduction of B-carotene-rich Orange sweet potato in rural Uganda resulted in increased Vitamin $A$ intakes among children and women and improved Vitamin A status among children. J Nutr. 2012;142(10):1871-80.

44. Ministry of Agriculture. Food security in Kenya. Republic of Kenya: Ministry of Agriculture; 2009.

45. Ministry of Agriculture Food Security and Cooperatives. Final report-Agriculture sector review and public expenditure review 2008/09. The United Republic of Tanzania: Ministry of Agriculture Food Security and Cooperatives; 2008

46. Ng CS, Dibley MJ, Agho KE. Complementary feeding indicators and determinants of poor feeding practices in Indonesia: a secondary analysis of 2007 Demographic and Health Survey data. Public Health Nutr. 2011;15(05):827-39.

47. Patel A, Pusdekar Y, Badhoniya N, Borkar J, Agho KE, Dibley MJ. Determinants of inappropriate complementary feeding practices in young children in India: secondary analysis of National Family Health Survey 2005-2006. Matern Child Nutr. 2012:8:28-44.

48. Jelliffe DB, Jelliffe EF. The volume and composition of human milk in poorly nourished communities: a review. Am J Clin Nutr. 1978;31(3):492-515.

49. Lönnerdal B. Effects of maternal dietary intake on human milk composition. J Nutr. 1986;116(4):499-513.

50. Kabir I, Khanam M, Agho KE, Mihrshahi S, Dibley MJ, Roy SK. Determinants of inappropriate complementary feeding practices in infant and young children in Bangladesh: secondary data analysis of Demographic Health Survey 2007. Matern Child Nutr. 2012;8 suppl 1:11-27.

51. Patel A, Pusdekar Y, Badhoniya N, Borkar J, Agho KE, Dibley MJ. Determinants of inappropriate complementary feeding practices in young children in India: secondary analysis of National Family Health Survey 2005-2006. Matern Child Nutr. 2012;8:28-44.

52. Bhandari N, Mazumder S, Bahl R, Martines J, Black RE, Bhan MK. An educational intervention to promote appropriate complementary feeding practices and physical growth in infants and young children in rural Haryana. India J Nutr. 2004;134(9):2342-8.

\section{Submit your next manuscript to BioMed Central and take full advantage of:}

- Convenient online submission

- Thorough peer review

- No space constraints or color figure charges

- Immediate publication on acceptance

- Inclusion in PubMed, CAS, Scopus and Google Scholar

- Research which is freely available for redistribution 